\title{
Tipping and Service:
}

\section{The Case of Hotel Bellmen}

\author{
Michael Lynn and Robert Gregor \\ School of Hotel Administration \\ Cornell University
}

in (2001) International Journal of Hospitality Management, 20, 299-303.

Correspondence concerning this article should be addressed to: Dr. Michael Lynn, 552

Statler Hall, School of Hotel Administration, Cornell University, Ithaca, NY 14850-6902, (607)255-8271, <WML3@Cornell.edu>. 


\title{
Tipping and Service:
}

\section{The Case of Hotel Bellmen}

\begin{abstract}
Social custom and psychological theory both suggest that hospitality customers leave tips as an incentive/reward for good service. However, previous research has found only a weak relationship between tips and service in restaurant settings. To see if this finding generalizes to other service contexts, we had a hotel bellman randomly assign his customers to receive either "limited service" or "full service" and to record the tips those customers gave him. The bellman's average tip was $\$ 4.77$ in the full service condition as compared to only $\$ 2.40$ in the limited service condition. This finding suggests that tipping does serve as a strong incentive/reward for bellmen to deliver good service.
\end{abstract}

Key Words: Tipping, Service, Hotel Bellmen 


\section{Tipping and Service:}

\section{The Case of Hotel Bellmen}

Consumers of hospitality services often give voluntary payments of money (called "tips") to the individuals who have served them. These tips are supposed to be an incentive/reward for service. In fact, economists argue that tipping exists because it is the most cost-effective way of providing servers with incentives/rewards for delivering good service (Bodvarrson of Gibson, 1994; Hemenway, 1984; Jacob \& Page, 1980).

In order for tipping to function as an incentive/reward, consumers must vary the sizes of their tips with the quantity and quality of the service they receive. Social custom and psychological theory both suggest that consumers will do this. Experts on social etiquette advise consumers to tip more for better service (Post, 1997). Psychologists argue that people are socialized to maintain an equitable balance between the benefits they receive from a relationship partner and the benefits they deliver to that partner (Adams, 1965; Walster, Berscheid \& Walster, 1973). Since hospitality customers get service and give tips in relationships with servers, this psychological theory (called "equity theory") suggests that consumers will give bigger tips when they get better service.

Despite the advise of etiquette books and the predictions of psychological theory, empirical studies of tipping in restaurants have generally found only weak relationships between tipping and service. For example, one meta-analytic review of 13 studies found an average correlation of only .11 between restaurant tip percentage and service evaluations (Lynn \& $\mathrm{M}^{\mathrm{c}}$ Call, 2000). Other studies have found similarly weak 
relationships between restaurant tips and various measures of server effort (Lynn, 1988, 1997; Lynn \& Grassman, 1990; Lynn \& Graves, 1986; Lynn \& Latane, 1984). These findings suggest that tipping may not provide an incentive/reward for delivering good service in restaurant settings. They also raise questions about the effect of service on the tips consumers leave in other service contexts. The present study begins to address these questions by examining the effects of service effort on the tips given to a hotel bellman.

\section{METHOD}

We had a bellman at a small luxury hotel in Ithaca, New York deliver one of two different levels of service to the newly arrived guests he escorted to their rooms. In the "limited" service condition, the bellman brought a cart up to the guests' car, greeted the guest, and loaded the guests' luggage onto the cart. After the guest checked into the hotel, the bellman accompanied him or her to the room, opened the door and brought the luggage into the room. Then the bellman asked the guest if they needed anything else, collected any offered tips, and left the room.

In the "full" service condition, the bellman did all the things mentioned above plus several additional things. After unloading the guests' luggage in the room, the bellman showed the guest how to operate both the television and the thermostat, opened the drapes to expose the room's view, and offered to bring the guest ice from a machine down the corridor. Then, he asked the guest if they needed anything else, collected any offered tips, and left the room.

A total of 50 guests were randomly assigned to either the limited or full service conditions described above. After delivering the appropriate level of service, the bellman recorded the guests' experimental condition, sex, apparent age, and tip. 


\section{RESULTS}

We found that the hotel bellman was rewarded for greater service efforts (see Table 1). He received an average tip of $\$ 2.40$ in the limited service condition and an average tip of $\$ 4.77$ in the full service condition. A t-test of the difference between these means indicated that they were significantly different from one another $(\mathrm{t}(48)=4.10, \mathrm{p}<$. 001).

The effect of service level on tips was not confined to any one group of consumers. Receiving full as compared to limited service increased men's tips by an average of $\$ 1.97$, increased women's tips by an average of $\$ 2.99$, increased younger (age $<50$ ) guests' tips by an average of $\$ 2.41$, and increased older (age $>49$ ) guests' tips by an average of $\$ 2.88$. Although it appears that service increased the tips of women and of older guests a little more than the tips of men and younger guests, F-tests of these sex-byservice and age-by-service interactions were not significant (both F's $(1,46)<1.0$, n.s.).

\section{DISCUSSION}

This study found that a hotel bellman was amply rewarded for greater service efforts. The bellman nearly doubled his tips by taking a few extra minutes to (a) inform guests how to operate the television and thermostat, (b) open the drapes in the room, and (c) offer to bring the guests ice! Clearly, for this bellman, and presumably for others as well, tipping does serve as a strong incentive/reward for delivering good service.

The service effect found in this study is much larger than that typically found in restaurants. The t-test value of 4.1 in this study converts to an effect size of $r=.51$ while 
the average service quantity and quality effects in restaurants have effect sizes of about $r$ $=.11$ (see Lynn 1997; Lynn \& $\mathrm{M}^{\mathrm{c}}$ Call, 2000). Perhaps tipping is less strongly related to service for restaurant waiters than for hotel bellman, because waiters have more prolonged contact with their customers than do bellman and because the norms for tipping waiters are more familiar and precise than are the norms for tipping bellman. More prolonged server-customer contact and more familiar and precise tipping norms both create social pressure that may simply overwhelm service considerations when consumers decide how much to tip restaurant waiters/waitresses. The weaker social pressures to tip hotel bellmen may give consumers greater freedom to consider service when deciding how much to tip hotel bellmen.

The managerial implications of these findings are straight forward. Previous research finding only a weak tipping-service relationship in restaurants suggests that restaurant managers cannot rely upon tipping to motivate waiters and waitresses to deliver good service (Lynn \& Graves, 1986; Lynn \& $\mathrm{M}^{\mathrm{c}}$ Call, 2000). The results of this study lead to a different conclusion regarding hotel bellmen. Hotel managers can rely upon tipping to motivate bellmen to deliver good service, because the tipping-service relationship appears to be strong and robust (across customer age and sex) in this context.

It is important to note that this study involved only one bellman at one hotel. Although this is similar to many studies of restaurant tipping that involved only one server at one restaurant (Lynn, 1988; Lynn \& Graves, 1996: Study 2; Rind \& Bordia, 1995), it does mean that caution must be used in generalizing the results to other bellman at other hotels. We can think of no specific reason for believing that the results will not generalize. Therefore, we feel confident that other bellmen at other hotels will also get 
substantially larger tips for better service. Nevertheless, this conclusion must be regarded as tentative until our results are replicated by others.

Some readers may also question our findings because of the small size of our sample - only 50 subjects. However, such concerns are misplaced. Sample size affects two things -- i.e., statistical power and the effectiveness of random assignment to conditions. With respect to statistical power, the question is whether or not the sample size is large enough to find a statistically significant relationship in the sample when that relationship exists in the population at large. The effect in this study was statistically significant, so our sample size was large enough to provide the needed statistical power. With respect to the effectiveness of random assignment, the question is whether or not the sample size was sufficient make the groups of subjects in the two conditions equal with respect to tipping propensities prior to the experimental manipulation. Since subjects were randomly assigned to conditions, any differences between the two groups prior to the experimental manipulation must arise by chance alone. However, our statistical test indicated that the post-manipulation differences in tipping between the two conditions were unlikely to be due to chance. Thus, our sample size was large enough to rule out chance differences in tipping propensity between the experimental conditions prior to the experimental manipulation. In short, our sample size was adequate for our purposes.

Finally, we would like to recommend that hotel chains use this study as a model for testing the effects on tipping of employees following company service policies. Companies can use their own service policies to define the full-service condition and can define the limited service condition by omitting some of the service steps called for in their service policies. By randomly assigning subjects to conditions and then comparing 
the average tips in each condition, companies can determine the casual effects of compliance with service policies on employees' tips. If following the service policies does increase tips, then this information can and should be passed on to employees to motivate compliance with the policies. If not, then perhaps the service policies themselves need to be re-examined. 


\section{REFERENCES}

Adams, J.S. (1965). Inequality in social exchange. In L. Berkowitz (Ed.). Advances in experimental social psychology, (Vol. 2). New York: Academic Press.

Bodvarsson, O.B. \& Gibson, W.A. (1994). Gratuities and customer appraisal of service: Evidence from Minnesota restaurants. Journal of Socio-Economics, 23, 287-302.

Hemenway, D. (1984). Prices and choices: Micro-economic vignettes. Cambridge, MA: Ballinger Publishing Co.

Hornik, J. (1993). Tactile stimulation and consumer response. Journal of Consumer Research, 19, 449-458.

Jacob, N. \& Page, A. (1980). Production, information costs, and economic organization: The buyer monitoring case. American Economic Review, 70, 476-478.

Lynn, M. (1988). The effects of alcohol consumption on restaurant tipping. Personality and Social Psychology Bulletin, 14, 87-91.

Lynn, M. (1997). The determinants of restaurant tipping: A meta-analytic review. Annual Conference of the Society for the Advanement of Behavioral Economics, Lexington, VA, June.

Lynn, M. \& Grassman, A. (1990). Restaurant tipping: An examination of three 'rational' explanations'. Journal of Economic Psychology, 11, 169-181.

Lynn, M. \& Graves, J. (1996). Tipping: An incentive/reward for service?

Hospitality Research Journal, 20, 1-14.

Lynn, M. \& Latane, B. (1984). The psychology of restaurant tipping. Journal of Applied Social Psychology, 14, 551-563. 
Lynn, M. \& McCall, M. (2000). Gratitude and gratuity: A meta-analysis of research on the service-tipping relationship. Journal of Socio-Economics, 29, 203-214.

Post, P. (1997). Emily Post's etiquette (16th Edition). New York: Harper Collins, pp. 532.

Rind, B. \& Bordia, P. (1995). Effect of server's "thank you" and personalization on restaurant tipping. Journal of Applied Social Psychology, 25, 745-751.

Walster, E., Berscheid, E. \& Walster, G.W. (1973). New directions in equity research. Journal of Personality and Social Psychology, 25, 151-176. 
TABLE 1

SUMMARY OF STUDY RESULTS

\begin{tabular}{|c|c|c|c|c|c|}
\hline EFFECT/CONDITION & $\begin{array}{c}\text { MEAN } \\
\text { TIP } \\
\end{array}$ & $\begin{array}{l}\text { STANDARD } \\
\text { DEVIATION }\end{array}$ & $\begin{array}{c}\text { SAMPLE } \\
\text { SIZE } \\
\end{array}$ & $\begin{array}{c}\text { STATISTICAL } \\
\text { TEST } \\
\end{array}$ & PROBABILITY \\
\hline SERVICE & & & & $\mathrm{t}(48)=-4.10$ & $\mathrm{P}<.0001$ \\
\hline LIMITED SERVICE & $\$ 2.40$ & 1.73 & 25 & & \\
\hline FULL SERVICE & $\$ 4.77$ & 2.31 & 25 & & \\
\hline SEX & & & & $\mathrm{t}(48)=0.54$ & $\mathrm{P}>.58$ \\
\hline MALE CUSTOMER & $\$ 3.73$ & 2.33 & 30 & & \\
\hline FEMALE CUSTOMER & $\$ 3.36$ & 2.42 & 20 & & \\
\hline AGE & & & & $\mathrm{t}(48)=-0.70$ & $\mathrm{P}>.40$ \\
\hline$<50$ Years & $\$ 3.37$ & 2.31 & 27 & & \\
\hline$>49$ Years & $\$ 3.84$ & 2.43 & 23 & & \\
\hline SEX X SERVICE INTERACTION & & & & $F(1,46)=0.70$ & $\mathrm{P}>.40$ \\
\hline MALE, Limited SERVICE & $\$ 2.62$ & 2.29 & 13 & & \\
\hline Male, Full Service & $\$ 4.59$ & 2.03 & 17 & & \\
\hline FEMALE, Limited SERVICE & $\$ 2.17$ & 0.83 & 12 & & \\
\hline FEMALE, FUll SERVICE & $\$ 5.16$ & 2.94 & 8 & & \\
\hline AGE X SERVICE INTERACTION & & & & $F(1,46)=0.01$ & $\mathrm{P}>.93$ \\
\hline$<50$, Limited SERVICE & $\$ 2.21$ & 1.19 & 14 & & \\
\hline$<50$, FULl SERVICE & $\$ 4.62$ & 2.60 & 13 & & \\
\hline$>49$, LiMITED SERVICE & $\$ 2.64$ & 2.29 & 11 & & \\
\hline _>49, FULL SERVICE & $\$ 4.94$ & 2.06 & 12 & & \\
\hline
\end{tabular}

